\title{
Fertility Trends in Finland ${ }^{1}$
}

\author{
By JARL LINDGREN
}

The Population Research Institute

The so-called demographic transition is said to have begun in Finland in the 1880 s, when the high mortality rate of the pre-industrial period slowly started to fall. The birth rate, however, did not show signs of declining until the 1920 s. Thereafter, on the whole, it has been constantly declining. The decline was relatively sharpest in the $1910 \mathrm{~s}$ and $1920 \mathrm{~s}$. The second world war broke this downward trend but it continued again in the 1950s. In the first part of the 1970s the birth rate reached an extremely low level — one of the lowest in the world - causing general concern. As a result of this declining birth rate the number of children per family has diminished further during this period of demographic transition, and childbearing is concentrated at the beginning of the reproductive period.

After a relatively short and rather drastic period of population change the situation in Finland now seems to be stabilizing anew. Population development and natural reproduction are about the same as before the demographic transition, although the developmental factors affecting these are balanced differently. Before the demographic transition an average of almost five children were born to each woman. Of these, however, only a little more than two reached maturity, which is somewhat more than the number of children per

1 This article is a synopsis of a study made by the author, the purpose of which is mainly to describe developmental trends in the decline of the birth rate during the demographic transition in Finland. However, it has not been possible to study birth rate trends from the beginning of the decline, thus the period under study covers the years between 1920-1970. The main emphasis of the study lies on research of cohorts. Although it has been necessary to resort to schematic reconstruction in the case of the older cohorts, which has leveled out traits and details typical to these cohorts, it is hoped that through this cohort analysis one can get a clearer picture of birth rate and fertility trends than is given by conventional cross-sectional methods. Leaning mainly on generally used data, the aim is to construct a picture of Finland as extensive and versatile as possible within the framework of statistics covering the country as a whole.

This article reports mainly the results of the study. Thus the method of procedure, which forms a separate part of the book, is referred to only briefly.

Jarl Lindgren. Suomalaisen syntyvyyden kehityskuva. The Population Research Institute Series B, No 38, 1975. 
family in the beginning of the 1970s. Thus the average number of descendants in the family has not diminished in the long run as steeply as is generally believed.

\section{The formation of cohorts}

Although there are facts available about population development in Finland covering a longer period of time than in most other countries, and although the present statistics in Finland are very good, they are still insufficient for the needs of birth rate and fertility research. Thus not until the year 1973 do the vital statistics in Finland show the number of births in relation to a woman's age and, at the same time, to the year of birth. Because of this it has not been possible to study fertility per birth cohort in its proper sense, instead cohorts have been used, formed by birth cohorts of two consecutive years.

The population statistics of Finland have been based since 1880 on a census gathered every ten years on the population present and since 1950 on a census made of the population actually living in the country. Since the population registers contained and still contain people who have moved out of the commune or are missing, the total number reported by the census is somewhat too large (Nieminen-Markelin 1974, 4-5). Thus it also follows that the special fertility rates, which have been based on this study on the number of women reported by the census, are probably somewhat underestimated.

Data on the number of women is available in Finland yearly according to the year of birth beginning in 1940. For the period before that corresponding data are available only for every ten years in connection with the census. Thus it is not possible to calculate the fertility of all the cohorts born between 19051925 directly from the data gathered from the statistics. In this study, also, it has been necessary to use different methods of calculation in forming the cohorts. The numerical data thus obtained, however, compose only about one seventh of the data showing the number of women. In principle the data have been obtained by taking the census figures per cohort and deducting from these the number of deaths up to the next census.

The number of live births are available by calendar year and, according to age of mother, for every year starting in 1940. Prior to that the number of live births was reported only in 5-year groups and before 1920 only every fifth year. Thus no distinction was made between live births and stillbirths before the year 1935. In order to get the needed information for the period prior to 1940, it has been necessary to use different methods of calculation. Because the number of children in the statistics are given by calendar year, they have been born to women of two consecutive birth cohorts. The size of a female cohort is the mean of two consecutive birth cohorts. 


\section{Cohorts in the light of fertility curves}

Age-specific fertility rates.

Age-specific fertility rates give a clear general view of fertility and its development. They do not give information on the factors governing fertility development, but they describe fairly accurately changes taking place in fertility.

During half a century there have been noticeable changes in the fertility of the cohorts. To cohorts born at the beginning of the century, a fairly long and level reproductive period was characteristic (Figure 1). Fertility reached its peak between the ages of 25 to 30 , and stayed high almost to the age of 40 after which it slowly declined.

Gradually the fertility curve squeezed together and became narrower. The reproductive period shortened and child birth was concentrated at the beginning of the reproductive period. The fertility curves of cohorts born in the 1920 s reached their peak in the ages between 25-27. The peak of the fertility curve moved over to increasingly younger age groups and, at the same time, to increasingly lower figures. The highest birth rate in cohorts born in the middle of the 1930 s was between the ages of $23-25$. In cohorts born after the war, primarily in the ones born $1945 / 46$ and $1946 / 47$, the peak was reached at the ages of 22 and 21. Characteristic to these cohorts is the fact that the birth rate in the first years of the reproductive period has been high, as high as in the cohorts born in the beginning of the 1930s and higher than those born in the beginning of the century.

Figure 1. Fertility curves of certain cohorts.

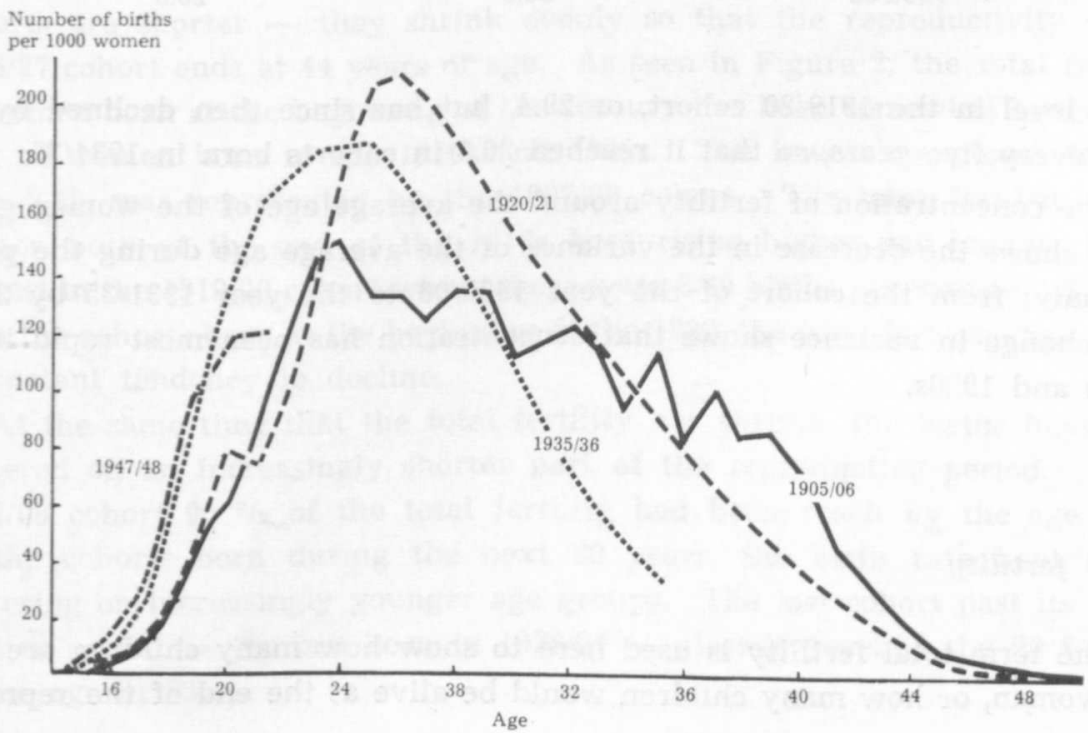


As seen in Figure 1, which shows the fertility curves of a few cohorts, the birth rate has not been steady. The fertility of the cohorts born at the beginning of the century has varied considerably from one year to the next. Part of the fluctuation is easily explained. So, for instance, the effects of the first year of the so-called continuation war, 1941, show up clearly in the 36th year of the cohort born in 1905/06, which corresponds to the year 1942. A corresponding decline in the birth rate can be seen in the 30 -year-olds of the $1909 / 10$ cohort and the 28-year-olds of the 1913/14 cohorts. The depression of the 1930 s also seems to be reflected in the fertility curves. The dip in the cohort curve of women born in 1905/06, which appears at the age of 27, corresponds to the year 1933. A corresponding dip appears in the 1909/10 cohort curve at the age of 23 . In the younger cohorts the fluctuations are considerably smaller.

A supplementary picture of the changes in birth timing is given by the average age of women giving birth, which has steadily declined. The average age at childbirth of the cohort born in $1905 / 06$ was 30.2 . It was still on the

$\mathrm{Table}$ 1. Average age of mothers giving birth in certain cohorts.

$\begin{array}{lcc}\begin{array}{l}\text { Birth year } \\ \text { of cohorts }\end{array} & \begin{array}{c}\text { Average age } \\ \text { of mothers } \\ \text { giving birth }\end{array} & \begin{array}{c}\text { Variance } \\ (\delta 2)\end{array} \\ 1905 / 06 & 30.3 & 45.4 \\ 1909 / 10 & 30.6 & 42.6 \\ 1914 / 15 & 30.1 & 37.9 \\ 1919 / 20 & 29.4 & 34.5 \\ 1924 / 25 & 28.3 & 31.8 \\ 1929 / 30 & 27.2 & 27.5 \\ 1934 / 35 & 26.3 & 25.5\end{array}$

same level in the $1919 / 20$ cohort, or 29.4 , but has since then declined by one year every five years, so that it reached 26.3 in cohorts born in 1934/35.

The concentration of fertility around the average age of the women giving birth shows the decrease in the variance of the average age during the period of study: from the cohort of the year $1905 / 06$ to the year $1931 / 35$ by $35 \%$. The change in variance shows that concentration has been most rapid in the 1910 s and 1920 s.

Total fertility

The term total fertility is used here to show how many children are born per woman, or how many children would be alive at the end of the reproduc- 
Figure 2. Actual total fertility of cohorts born 1905/06-1930/31 and forecasted total fertility of cohorts born 1931/32-1944/45.

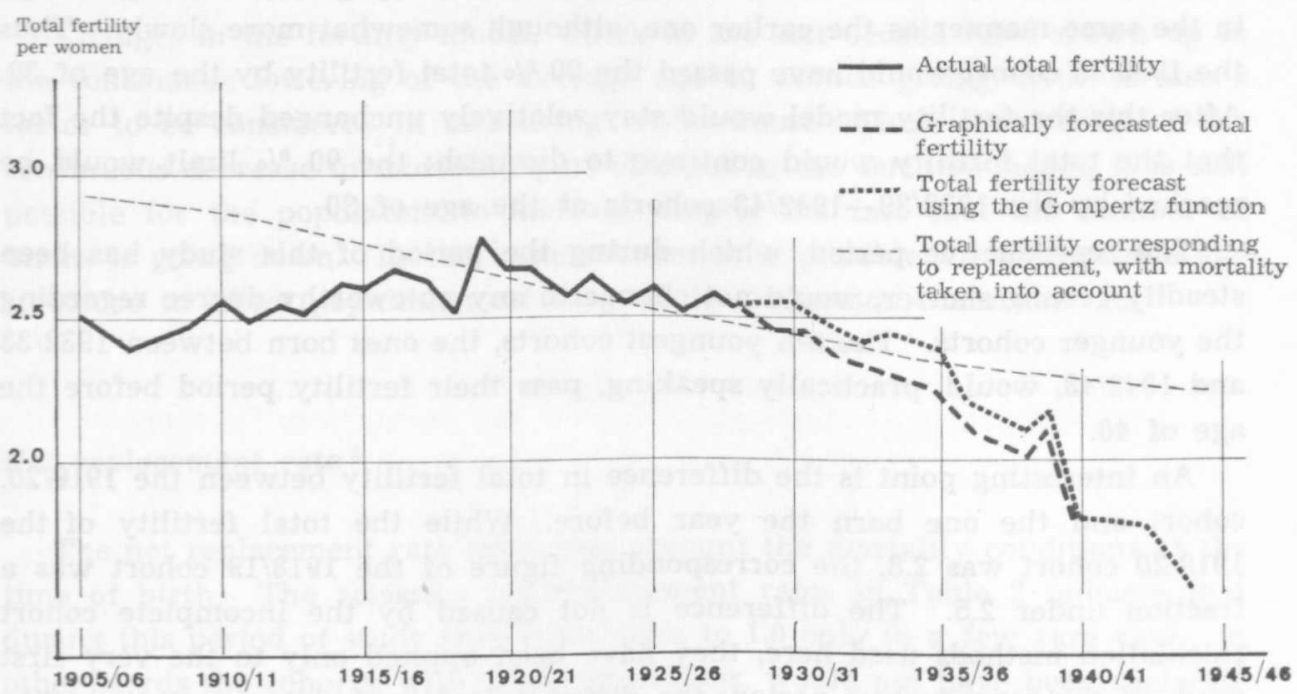

tive period if there had been no mortality. The total fertility of the cohorts under study, which is the sum of the age-specific fertility rates, has stayed fairly level during the period under research. Thus the 22 women cohorts studied here, whose birth dates reach from the year 1905/06 to 1926/27, have given birth to $2.45-2.65$ children per woman, except a few rare years in which the total fertility has been somewhat higher or lower. Of the cohorts under study the main body is made up of those, whose reproductive period reaches up to 50 years of age. However, the real reproductive periods of the last seven cohorts are shorter - they shrink evenly so that the reproductivity of the 1926/27 cohort ends at 44 years of age. As seen in Figure 2, the total fertility of women born at the beginning of the century has been somewhat lower than that of women born in the 1910s and 1920s. The lowest completed fertility rate, 2.42 , was represented by the $1907 / 08$ cohort. The total fertility of the women born at the end of the 1910 s kept rising higher and higher. It was highest in the 1919/20 cohort where there were 2.80 births per women. Starting with the cohorts born at the beginning of the 1920, the total fertility has shown a constant tendency to decline.

At the same time that the total fertility has shrunk, the births have been centered on an increasingly shorter part of the reproductive period. In the $1905 / 06$ cohort $90 \%$ of the total fertility had been reach by the age of 39 . In the cohorts born during the next 20 years, the birth rate kept slowly centering on increasingly younger age groups. The last cohort past its reproductive period - the one born in 1926/27 — already reached the $90 \%$ limit at the age of 35 . 
The development of the end of the reproductive period of the succeeding cohorts, which have been determined graphically, (cf. page 81), would continue in the same manner as the earlier one, although somewhat more slowly. Thus the $1935 / 36$ cohort would have passed the $90 \%$ total fertility by the age of 32 . After this the fertility model would stay relatively unchanged despite the fact that the total fertility would continue to diminish: the $90 \%$ limit would be reached by the 1938/39-1942/43 cohorts at the age of 30 .

The reproductive period, which during the period of this study has been steadily getting shorter, would not change to any noteworthy degree regarding the younger cohorts. The ten youngest cohorts, the ones born between 1932/33 and $1942 / 43$, would, practically speaking, pass their fertility period before the age of 40 .

An interesting point is the difference in total fertility between the $1919 / 20$, cohort and the one born the year before. While the total fertility of the $1919 / 20$ cohort was 2.8 , the corresponding figure of the $1918 / 19$ cohort was a fraction under 2.5. The difference is not caused by the incomplete cohort calculation methods used here, they have been applied only to the very first years of the reproductive period: the differences do not show up until beginning at the age of twenty and a half. To some degree the difference is caused by the fact that here the mean population has been used. Since there were great differences in the number of children born during the years 1918-19 the mean population is a too rough approximation for calculating the fertility rates: it would have been better to use monthly figures. ${ }^{2}$

Since the birth rate in both cohorts has stayed about the same up till the war years of $1939-44$, but after that has been lower in the 1918/19 cohort compared to the $1919 / 20$ cohort, it seems however, in addition, that for some unknown reason the former cohort would have been more affected by the war than the latter.

\section{Replacement}

The replacement of the population and ways to measure this have continued to intrigue demographers. Yet no indicator has so far been discovered, which would give a completely accurate picture. The reason for this is the fact that replacement depends on many factors, which are very hard to connect with one and the same indicator. Thus replacement is not dependent merely on the number of births, as is assumed when using gross replacement rates. It is also dependent on mortality. If, on the other hand, the mortality rate steadily declines, as it has done during the demographical transition, taking into account the prevailing mortality at birth is not sufficient to form a clear picture of replacement. One also has to take into consideration the steady decrease in

2 I am indepted to professor Gunnar Fougstedt for this observation. 
The classic net replacement rate of the cohorts born at the beginning of the century has been around $0.8-0.9$. In the cohorts born in the $1920 \mathrm{~s}$ the rate exceeds 0.9 and is close to 1.0 .

The net replacement rates of the cohorts not yet past their reproductive period, which have been arrived at using graphically obtained specific fertility rates (cf. page 81), would, up to the cohort born in the early 1930 s, stay on the same level as previous cohorts past their fertility period, or very close to 1.0. Taking into consideration the continuous decrease in mortality, the reproduction rates of these cohorts would such have been sufficient to guarantee their replacement. Slowly, however, the net replacement rates started to go down reaching the low level of 0.70 in the cohorts born in $1942 / 43$ - which is the last cohort studied here.

The net replacement rate shows that for the main part of the cohorts studied, fertility has not been sufficient to replace the generation, in other words the completed fertility of these cohorts would be smaller than the original cohorts. Nevertheless the population of Finland has continuously increased. So the net replacement rate does not give a correct picture of the situation and is thus not the best possible indicator of population replacement. If mortality keeps going down, it follows that we need fewer descendants than what the life expectancy figures at birth would show. The diminishing mortality has primarily taken place among the young age groups. After reaching its fertility period the female cohort is thus numerically larger than what the life expectancy at birth would indicate. In that way the net replacement rate underestimates actual replacement, because it only takes into consideration conditions prevailing at birth.

The probability of death in Finland have dropped steadily from the turn on the century until the war years. The decrease has been especially noticeable in the young age groups. After the war years it has continued even faster than before. The decrease in mortality has been especially marked among women. The average life expectancy of a newborn female child has increased from 48.1 years to 72.6 or by $50 \%$ from the years $1901-10$ to $1961-65$.

Since the birth rate is naturally dependent on the number of women of fertile age, the effect of the declining death rate on the rate of birth can best be illuminated by taking into consideration the changes in the sizes of the age groups. This can be done by comparing the total lifetimes of different generations. The total number of person-years lived gives a better picture of mortality and survival than could be gathered from life tables, especially when one wants to measure the intensity of the activity of a given population group.

Calculating the total person-years lived of a generation requires observation of a rather long time interval. It is, however, possible to use an abridged mortality table in calculating the number of person-years lived. Since the length of a generation can be considered approximately 30 years, the life expectancy of two successive generations can be compared every 30 years. To 
indicate total number of person-years lived, we have used here the time indicating how many years per woman the cohort has accumulated by the time the cohort has reached the age of 50 .

Calculating the number of person-years lived required the use of life tables of the cohort in question. Since these are not available in Finland, it was necessary in this study to prepare life tables for five cohorts by combining figures gathered from different life tables.

The cohort mortality was determined for five cohorts only, because life tables for the first part of the period under study had been published only every ten years, and it was not felt necessary to calculate cohort life tables for more than those born every tenth year.

As a result of the diminishing mortality, the life expectancy determined for the cohorts was as usual; compared to the figures derived from the life tables, it was 4-6\% longer, except for the first cohort born in 1905, whose life expectancy was only $2.6 \%$ longer.

Comparison between the number of person-years lived shows that the lifetime of cohorts has increased since 1905 every 30 years by approximately $11-$ $12 \%$. If, to simplify things, we start with the fact that during the observation period the mortality situation from one generation to the next had improved by $12 \%$, we find that replacement had been considerably better than what the classic net replacement rates would indicate. Replacement would not stay under 0.9 in one single year, and under 1.0 in only the first ten cohorts (Table 3). Starting in the middle of 1919 the replacement of the cohorts has, as a result of a continuously diminishing mortality, been sufficient to indicate a clear, though small, population increase, which at the end of the observation

Table 3. Replacement according to corrected replacement rate.*

$\begin{array}{llll}\begin{array}{l}\text { Birth year } \\ \text { of cohort }\end{array} & \text { Birth year } & \\ 1905 / 06 & 0.92 & \begin{array}{l}\text { of cohort } \\ 1916 / 17\end{array} & 1.01 \\ 1906 / 07 & 0.91 & 1917 / 18 & 1.00 \\ 1907 / 08 & 0.90 & 1918 / 19 & 1.00 \\ 1908 / 09 & 0.92 & 1919 / 20 & 1.13 \\ 1909 / 10 & 0.93 & 1920 / 21 & 1.08 \\ 1910 / 11 & 0.95 & 1921 / 22 & 1.06 \\ 1911 / 12 & 0.95 & 1922 / 23 & 1.04 \\ 1912 / 13 & 0.95 & 1923 / 24 & 1.12 \\ 1913 / 14 & 0.96 & 1924 / 25 & 1.10 \\ 1914 / 15 & 0.99 & 1925 / 26 & 1.11 \\ 1915 / 16 & 0.99 & 1926 / 27 & 1.08\end{array}$

* Classic net replacement rates have been raised by the lengthening of average lifetime indicated by person-years lived. 
period again showed signs of decreasing. On the average, the corrected replacement rate of cohorts born in 1905/06-1926/27 has been about 1.0.

Although they are determined by taking into account the development of death rates, the net replacement rates per cohort have during this study generally been considerably lower than ordinary periodic net replacement rates obtained by cross-sectional methods.

\section{Childlessness and replacement}

Although changes in mortality are taken into account when calculating the replacement rate, it still does not give a complete picture of replacement. In addition to changes in mortality you also have to consider the fact that a certain number of women, for some reason or other, never have children. In the following calculation this fact has been taken into account, so the result shows how many children should be born per family or rather per woman, so that the population would replace itself.

The most important reason for infertility is female sterility. According to the fertility study done by the Bureau of Statistics, $15 \%$ of first marriages were childless.

On the basis of data gathered from the fertility study the whole ratio of childless marriages can be estimated at $10 \%$, when one considers the division of childless marriages according to age at time of wedding. This includes not only physiological sterility but also voluntary childlessness.

In addition to sterility one also has to take into account the unmarried, who are also childless, when calculating the replacement rate. According to the fertility study mentioned earlier, $81-86 \%$ of all women had married once. It can be determined that about $15 \%$, maybe a little less, of all women were unmarried. Some of these women, however, have given birth. According to the fertility study, unmarried mothers formed $6.3 \%$ of all women giving birth. The ratio of unmarried and at the same time childless women has thus been about 8-9\% of all women. Using these figures, it can be concluded that about $18 \%$ of all women, for reasons of physiological sterility, voluntary childlessness, illness or unmarried state, do not contribute to the replacement of the population.

Since more boys are born than girls, this also has to be taken into account. We have used here the figure 0.488 as the ratio of girls to boys in all births. If mortality, sterility or childlessness in all its forms are not considered, it follows from this that 2.05 children per woman would be enough to keep the population unchanged from one generation to another.

If you take into account sterility in marriage plus the sex ratio at birth but not mortality, there should be about 2.50 children born per woman, when you also consider that $18 \%$ of all women remain childless for one reason or another (Figure 3). 
Figure 3. Diagram showing the ratio of childless women and women who have borne children out of all women, and how many children should be born per woman in order for the population to replace itself, taking into account childlessness and mortality.

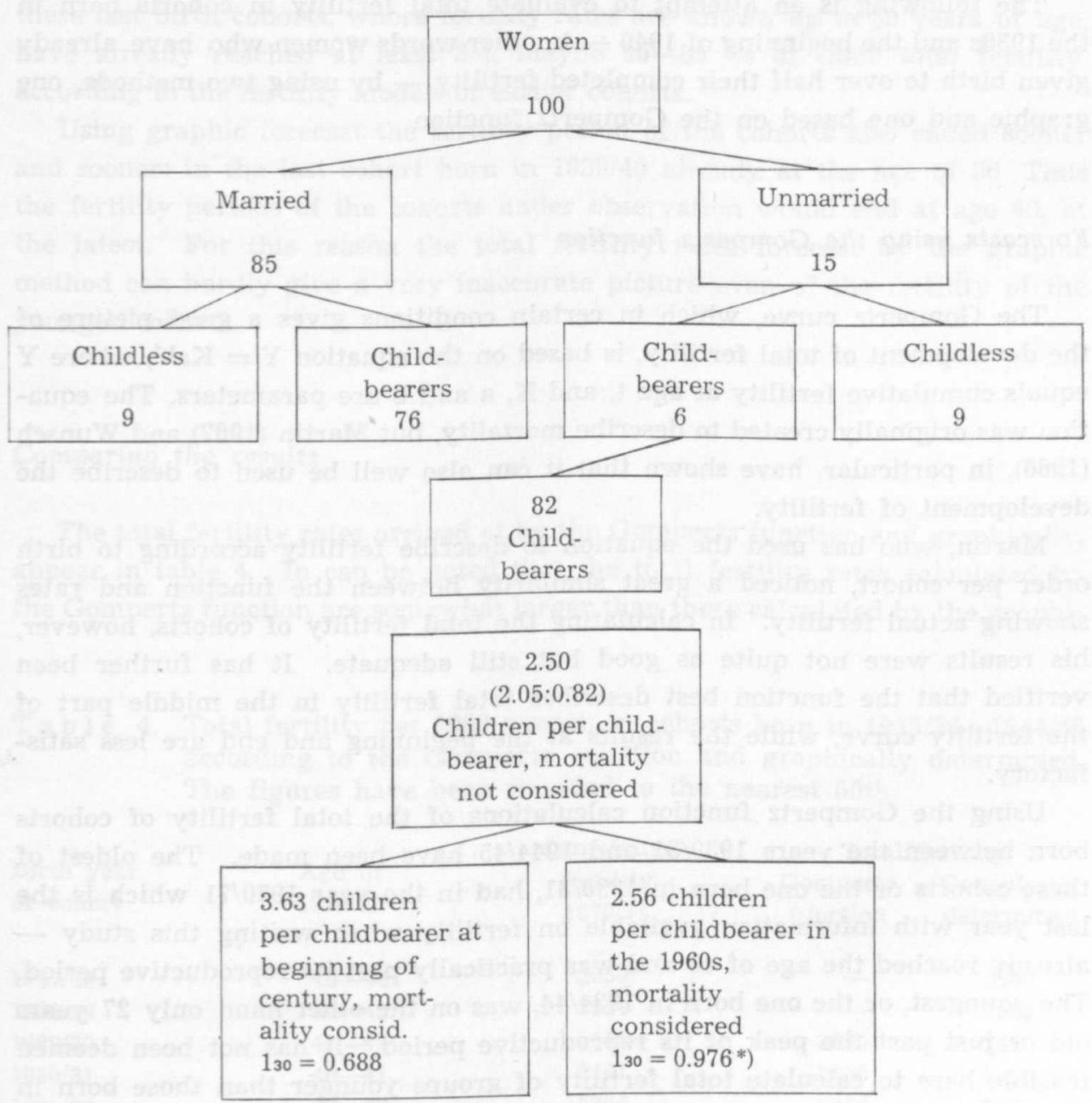

* Life tables 1965-70 Preliminary data Bureau of Statistics VA 1973: 15.

\section{Fertility forecast}

In social planning it is important to know the fertility trends and total fer. tility of cohorts that have not yet passed their reproductive period. Efforts of this kind have been made during the past few years using different methods. 
The greatest interest has been in determining total fertility, which has mainly been done using the so called Gompertz function. There have also been attempts to find a function that would show the shape of the fertility curve according to age. Examples are Hadviger's function and the Gamma functions.

The following is an attempt to evaluate total fertility in cohorts born in the 1930 s and the beginning of 1940 - in other words women who have already given birth to over half their completed fertility - by using two methods, one graphic and one based on the Gompertz function.

\section{Forecasts using the Gompertz function}

The Gompertz curve, which in certain conditions gives a good picture of the development of total fertility, is based on the equation $\mathrm{Y}=\mathrm{Kab}$, where $\mathrm{Y}$ equals cumulative fertility at age $t$, and $K$, $a$ and $b$ are parameters. The equation was originally created to describe mortality, but Martin (1967) and Wunsch (1966), in particular, have shown that it can also well be used to describe the development of fertility.

Martin, who has used the equation to describe fertility according to birth order per cohort, noticed a great similarity between the function and rates showing actual fertility. In calculating the total fertility of cohorts, however, his results were not quite as good but still adequate. It has further been verified that the function best describes total fertility in the middle part of the fertility curve, while the results at the beginning and end are less satisfactory.

Using the Gompertz function calculations of the total fertility of cohorts born between the years 1930/31 and 1944/45 have been made. The oldest of these cohorts or the one born in $1930 / 31$, had in the year 1970/71 which is the last year with information available on fertility when writing this study already reached the age of 40 and was practically past its reproductive period. The youngest, or the one born in 1934/44, was on the other hand only 27 years old or just past the peak of its reproductive period. It has not been deemed feasible here to calculate total fertility of groups younger than those born in $1944 / 45$.

\section{Graphic forecasting}

In addition to the Gompertz curve there was also an attempt to estimate the last phase of the fertility period graphically in such a manner that the specific fertility curves were drawn similarly to the fertility curves of the last cohorts past their reproductive period, or those born in 1927/28.

It is fairly easy to determine the extension of the fertility curve in the older cohorts, where the unknown part of the curve is very small and thus has little 
significance for total fertility. As you move over to the curves of younger cohorts it becomes progressively more difficult to draw the curve. For this reason we have not wanted here to forecast graphically the development of the fertility curve in cohorts younger than those born in 1939/40. However, these last birth cohorts, whose fertility rates are known up to 30 years of age, have already reached at least $3 / 4$, maybe $80-85 \%$ of their total fertility, according to the fertility models of earlier cohorts.

Using graphic forecast the fertility period of the cohorts also ended sooner and sooner: in the last cohort born in 1939/40 already at the age of 36 . Thus the fertility periods of the cohorts under observation would end at age 40, at the latest. For this reason the total fertility rates forecast by the graphic method can hardly give a very inaccurate picture even of the fertility of the younger cohorts.

Comparing the results

The total fertility rates arrived at by the Gompertz function and graphically, appear in table 4 . In can be noted that the total fertility rates calculated by the Gompertz function are somewhat larger than those calculated by the graphi-

T a b le 4. Total fertility per 1000 women in cohorts born in 1935/36-1944/45 according to the Gompertz equation and graphically determined. The figures have been rounded to the nearest 50 th.

$\begin{array}{lcccr}\begin{array}{l}\text { Birth year } \\ \text { of cohort }\end{array} & \begin{array}{c}\text { Age in } \\ 1970 / 71\end{array} & \begin{array}{c}\text { Cumulative } \\ \text { fertility } \\ 1970 / 71\end{array} & \begin{array}{c}\text { Total } \\ \text { Gompertz } \\ \text { function }\end{array} & \begin{array}{r}\text { fertility } \\ \text { fraphically } \\ \text { determin }\end{array} \\ 1927 / 28 & 43-44 & 2558 & - & 2560 \\ 1928 / 29 & 42-43 & 2521 & - & 2550 \\ 1929 / 30 & 41-42 & 2445 & 2550 & 2450 \\ 1930 / 31 & 40-41 & 2431 & 2550 & 2450 \\ 1931 / 32 & 39-40 & 2364 & 2450 & 2400 \\ 1932 / 33 & 38-39 & 2300 & 2450 & 2300 \\ 1933 / 34 & 37-38 & 2260 & 2400 & 2300 \\ 1934 / 35 & 36-37 & 2223 & 2400 & 2250 \\ 1935 / 36 & 35-36 & 2157 & 2200 & 2100 \\ 1936 / 37 & 34-35 & 2015 & 2150 & 2050 \\ 1937 / 38 & 33-34 & 1957 & 2100 & 2000 \\ 1938 / 39 & 32-33 & 1864 & 2150 & 2100 \\ 1939 / 40 & 31-32 & 1878 & 1800 & 1800 \\ 1940 / 41 & 30-31 & 1547 & 1800 & - \\ 1941 / 42 & 29-30 & 1490 & 1750 & - \\ 1942 / 43 & 28-29 & 1375 & 1650 & - \\ 1943 / 44 & 27-28 & 1258 & 1400 & - \\ 1944 / 45 & 26-27 & 1004 & & \end{array}$


cal method. The difference remains fairly even during the whole period of observation, in the younger cohorts it is, however, a little smaller.

The total fertility determined by the graphic method is especially in the older cohorts, only a fraction larger than the cumulative specific fertility in 1970/71. Also, in the younger cohorts, the difference is comparatively small, and this is caused by the fact that using the graphic method, the cohort fertility periods end sooner and sooner, in all cohorts under 40 years of age. Although it is fairly safe to assume that this is not categorically true in real life, the number of children born at the end of the fertility period hardly has any significance as to total fertility. The total fertility of the youngest cohort, or the one born in $1940 / 41$, would be 1.80 per woman while the cumulative specific fertility would be 1.55 per woman in 1970/71.

The total fertility rates calculated by the Gompertz function have been computed further than those arrived at by the graphic method. The closer you get to younger cohorts the more these rates correspond to each other. This probably depends on the nature of the Gompertz curve. It describes the cumulative fertility curve better, the closer the age fertility curve gets to a bellshape. For this reason it seems possible, that the total fertility rates calculated by the Gompertz function are somewhat overestimated especially in the older cohorts, while by the graphic method they apparently have been estimated a little too low.

\section{Condensation and final remarks}

Cohorts born in the beginning of the century were characterized by a fairly long and even fertility period. Fertility reached its peak already at the age of 24-28 and stayed relatively high almost to the age of 40 . For cohorts born in the period 1905-1920 mean-age of childbearing stayed continuously at 30 . Gradually, however, the fertility period shortened and childbirth centered more and more on the beginning of the reproductive period, as the changes in the average age of women giving birth show: the mean-age of childbearing of women born in the middle of the $1930 \mathrm{~s}$ had dropped to 26 . The changes in fertility have, however, been relatively small and slow up to the cohorts born after the second world war, when the peak of the fertility curve rapidly moved to increasingly younger age groups and at the same time to increasingly lower rates. Typical of the post-war cohorts has been the fact that the birth rate in the first years of the fertility period has been fairly high, as high as at the beginning of the 1930 s and even higher than in cohorts born at the beginning of the century.

The centering of childbirth on increasingly younger age groups also becomes apparent in the shortening of the reproductive period. While in the 1905/06 birth cohorts $90 \%$ of total fertility was reached at 39 years of age, the cor- 
responding figure in the cohorts born in the middle of the 1930 s was 32 years of age. Since then or up to the cohorts born in the beginning of the $1940 \mathrm{~s}$, which are the last cohorts included in the study, it has remained relatively unchanged. When the projected total fertility of the cohort born in 1939/40 was still 2.1, the total fertility of the next birth cohort would drop to 1.7. If the cohorts born in the beginning of the 1940 s, of which the oldest would have reached the age of 25 by 1970, would follow the same fertility pattern as the previous cohorts, their total fertility would be only about 1.5-1.6 per woman. It is of course possible that these cohorts have postponed getting children to a later date and that their fertility will decline more slowly than has been assumed here. These cohorts born in the middle of the 1940 s show that after the highest rates fertility has slowly declined. These age groups, who have felt superfluous everywhere - who have had trouble getting into schools and later finding a job - have had no other resource than to limit childbirth more effectively than previous cohorts.

The net replacement rate calculated in the classic way has throughout the observation period been almost consistently under 1.0, in other words the birth rate would not have been sufficient for the replacement of the population. Despite this the Finnish population has grown continuously.

Thus the net replacement rate has not given a correct picture of the situation. A result of the continuously growing lifespan has been the fact that less descendants have been needed than the net replacement rate based on life tables would indicate. The female cohort has been more numerous than could be concluded from the life tables prevailing a birth. Quite a different picture is arrived at when the declining mortality is taken into account. Then the replacement rate shows that, with the exception of the cohorts born before the middle of the $1910 \mathrm{~s}$, the birth rate has been high enough to guarantee replacement at least up to the cohorts born at the end of the $1930 \mathrm{~s}$. The birth rate of the later cohorts has fairly rapidly drawn away from the total fertility needed for replacement: for the cohorts born at the beginning of the 1940s it should be 2.3 per woman, but the projected total fertility is only 1.7.

Finally it can be concluded that the population growth during the observed period is almost solely a result of the declining death rate. Nevertheless, fertility despite its continuous diminishing has up to the 1960 s had a part in population growth. Although fertility by age diminishes, it is possible for the population to grow temporarily, if the changes in age structure lead to the growth of fertile age groups.

During the period of observation there does not, however, appear noticeable changes in the age structure of women of fertile age. Thus the reasons have to be searched for elsewhere. And it is found primarily in the fertility pattern, which is characterized by the shifting over of fertility to younger age groups. As a result the average age of women giving birth has declined and thus the distance between generations has also shortened. When this distance shortens, new generations are born at a faster pace. This explains why the population 
keeps growing despite the fact that fertility decreases and mortality is unchanged. In the 1960 s fertility had dropped so low that it has hindered the quantitative development of the population. The diminishing mortality, however, has evened out the effect that the decreasing fertility has on population change.

\section{References}

Central Statistical Office of Finland. Official Statistics of Finland. Life tables 1901$10,1911-20,1921-30,1931-35,1936-40,1941-45,1946-50,1951-55,1956-60$, 1961-65.

Martin Peter. Une application des fonctions de Gompertz á l'étude de la fécondité d'une cohorte. Population n:o 6. 1967, pp. 1085-1096.

Nieminen, Mauri - Markelin, Pasi. Suomen väestökirjanpito ja väkiluvun laskeminen. Tilastokeskus, Muistio 27. Helsinki 31. 7. 1974.

Tilastotiedotus VL 1972:5. Tutkimus lasten lukumäärästä. Central Statistical Office of Finland. Helsinki 1972.

Wunsch, G. Courbes de Gompertz et perspectives de fécondité. Recherches Economiques de Louvain 32 (6): 457-468. Louvain 1966. 
mortality as well as changes in its structure. This can be done, for instance, by using the number of years lived as indicators of mortality.

Changes in the fertility model, which in the last decade have shown up in the continuous lowering of the average age of women giving birth, is also a factor to be considered in measuring replacement. Thus, as a result of the continuous decrease in mortality plus changes in the fertility model, it is still possible for the population to increase despite the fact that the number of births is going down. In the same manner it is possible for a favorable age structure to affect population increase while emigration diminishes it.

Net replacement rate ${ }^{3}$

The net replacement rate takes into account the mortality conditions at the time of birth. The "classic» net replacement rates in Table 2 indicate that during this period of study they came close to 1.0 only in a few rare cases, in other words the cohorts, with a few exceptions, would not have been replaced.

Table 2. Replacement according to classic net replacement rate.*

$\begin{array}{llll}\begin{array}{l}\text { Birth year } \\ \text { of cohort }\end{array} & & \begin{array}{l}\text { Birth year } \\ \text { of cohort }\end{array} & \\ 1905 / 06 & 0.82 & 1924 / 25 & 0.98 \\ 1906 / 07 & 0.81 & 1925 / 26 & 0.99 \\ 1907 / 08 & 0.80 & 1926 / 27 & 0.96 \\ 1908 / 09 & 0.82 & 1927 / 28 & 0.98 \\ 1909 / 10 & 0.83 & 1928 / 29 & 1.03 \\ 1010 / 11 & 0.85 & 1929 / 30 & 0.99 \\ 1911 / 12 & 0.85 & 1930 / 31 & 0.99 \\ 1912 / 13 & 0.85 & 1931 / 32 & 0.96 \\ 1913 / 14 & 0.86 & 1932 / 33 & 0.94 \\ 1914 / 15 & 0.88 & 1933 / 34 & 0.93 \\ 1915 / 16 & 0.88 & 1934 / 35 & 0.92 \\ 1916 / 17 & 0.90 & 1935 / 36 & 0.90 \\ 1917 / 18 & 0.89 & 1936 / 37 & 0.85 \\ 1918 / 19 & 0.89 & 1937 / 38 & 0.83 \\ 1919 / 20 & 1.01 & 1938 / 39 & 0.82 \\ 1920 / 21 & 0.96 & 1939 / 40 & 0.87 \\ 1921 / 22 & 0.95 & 1940 / 41 & 0.73 \\ 1922 / 23 & 0.93 & 1941 / 42 & 0.74 \\ 1923 / 24 & 1.00 & 1942 / 43 & 0.70\end{array}$

* Calculations based on mortality conditions prevailing at birth.

3 In measuring population replacement it has not been possible here to take external migration into account. Thus, the replacement figures describe the replacement of the closed population. 